\title{
What cognitive representations underlie social attitudes?
}

\author{
ANTHONY G. GREENWALD \\ University of Washington, Seattle, Washington
}

\begin{abstract}
An attitude is the evaluation or affect associated with a social object. A theory of attitudes should specify (1) how attitude objects are represented, and (2) what kind of representation constitutes an attitude. To the first question, social psychologists long ago anticipated answers that are now attractive to cognitive psychologists. On the second, social psychologists are in need of help that can come from recent cognitive psychological work on unconscious processes.
\end{abstract}

An attitude is the evaluation or affect associated with a social object. From its beginnings in the 1920 s, the study of attitudes has directed theoretical attention to social objects. Social objects are such things as people (for example, friends or political candidates), categories of people (such as racial and ethnic groups), or abstract concepts (such as abortion rights or God).

Social psychologists have long interpreted attitude objects as abstract mental representations. This cognitive conception of motivation was notable for its deviation from the reductionist physical stimulus approach to motivation in experimental psychology before 1960, and it anticipated by many years the development of motivational concepts such as goals and plans in cognitive psychology.

A problematic aspect of the nature of representations associated with attitudes concerns the nature of representations that constitute attitudes themselves. Social psychology presently has two well-formulated conceptions of the structure of attitudes. One is that attitudes have a tripartite structure, consisting of affective, cognitive, and conative components (e.g., Breckler, 1984; Ostrom, 1968). The tripartite conception originates in an ancient partition of mental life into affect, cognition, and conation. (That ancient trichotomy appears to have been effectively undermined by modern cognitive psychology, but that is a story for another occasion.) A second widely held view of attitude structure is that attitudes consist of proposition-like representations of the attitude object's attributes (e.g., Fishbein, 1967b).

I will conclude that these two answers, both of which have found wide acceptance in social psychology, are not very useful. Furthermore, it appears that there is now a good chance to base a new and useful understanding of the structure of attitudes on recent work by cognitive psychologists.

Preparation of this report was assisted substantially by Grant MH-41328 from the National Institute of Mental Health. The author is especially grateful to Mahzarin R. Banaji and Mitzi M. S. Johnson for use of previously unpublished data. Correspondence may be addressed to Anthony G. Greenwald, Department of Psychology, NI-25, Seattle, WA 98195.

\section{State of the Art of Attitude Measurement}

The argument can be started with a description of the current state of the art of attitude measurement. The most widely used techniques can be illustrated with items for which the attitude object is social psychology itself. These items are similar in structure to ones that could be used for assessing attitudes toward almost any social object.

The semantic differential technique, developed by Osgood (Osgood, Suci, \& Tannenbaum, 1957), requests a series of judgments of the attitude object on bipolar evaluative scales, such as that in Figure 1.

The equal-appearing interval technique, developed by Thurstone (Thurstone \& Chave, 1929) employs a series of about 20 statements that have previously been scaled for degree of favorability toward the object, and are selected to have scale values distributed evenly across the range of favorability. Attitude is measured as the median scale value of items endorsed by the subject. Figure 2 presents three possible items that represent, respectively, anti-, moderate, and pro-, attitudes.

The summated ratings technique, developed by Likert (1932), uses items similar to ones that would be located at or near the extreme positions of an equal-appearing interval scale. The attitude measure is the sum of the subject's endorsement scores for each item, reversing the endorsement scale for anti- worded items, such as the first of the two in Figure 3.

The multiattribute rating technique, developed by Fishbein (Fishbein, 1967b), requires separate assessment

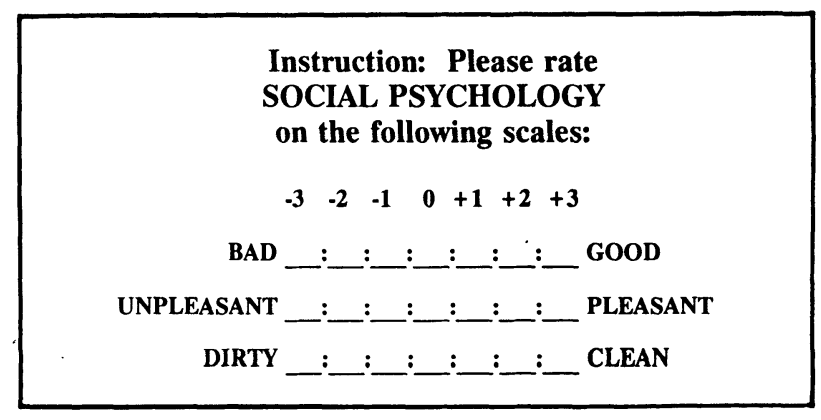

Figure 1. Illustration of the Osgood semantic differential attitude measurement procedure. 


\section{Instruction: Check each statement that expresses your sentiment toward SOCIAL PSYCHOLOGY.}

I think the content of social psychology is altogether too superficial to have much social significance.

I respect social psychology, but I seldom read articles in social psychology journals.

Social psychological research is among the most methodologically sophisticated in psychology.

Figure 2. Illustration of the Thurstone equal-appearing intervals attitude measurement procedure.

Instruction: Indicate your degree of approval of each statement, where

$$
\begin{aligned}
& 1=\text { Strongly Disapprove } \\
& 2=\text { Disapprove } \\
& 3=\text { Undecided } \\
& 4=\text { Approve } \\
& 5=\text { Strongly Approve }
\end{aligned}
$$

I believe that social psychology is hopelessly out of date.

I believe that social psychology can effectively address social problems associated with prejudice toward minority groups.

Figure 3. Ilustration of the Likert summated ratings attitude measurement procedure.

of the subject's (1) belief in the relation of an object to each of a series of attributes, and (2) evaluation of those attributes. Attitude is computed as an average of the attribute evaluations, each weighted by the strength of its relation to the attitude object (see Figure 4).

\section{Concerns about Construct Validity of the Attitude Concept}

Attitude measures such as the ones just illustrated provide a rational basis for measuring attitudes on interval scales. In terms of the representational approach to measurement (e.g., Coombs, Dawes, \& Tversky, 1972) there is a problem with these measures, because they cannot be demonstrated to meet the empirical-relational assumptions for interval scales. However, this concern about numerical interpretation pales in comparison with concerns raised by the limited ability of such scales to predict behavior. In many research settings, measures of attitude do not correlate well with measures of behavior toward the attitude object. This concern, often referred to as the attitude-behavior problem, was first pointed out emphatically in a literature review by Wicker (1969). The attitude-behavior problem poses a major difficulty for cognitive social psychology.
The attitude-behavior problem is not the only major concern about construct validity of the attitude concept. In addition, the vast body of experimental research on attitude change or persuasion can be characterized as a collection of weak and difficult-to-replicate effects (this was first pointed out by Ronis, Baumgardner, Leippe, Cacioppo, \& Greenwald, 1977). As just one example of the fragility of persuasion effects, consider the sleeper effect, which was one of the first persuasion findings described in the modern era of attitude change research (which began with the work of Hovland, Lumsdaine, and Sheffield [1949] for the Office of Strategic Services during World War II). Years after the sleeper effect had become established as a standard result that appeared regularly in introductory textbooks, Cook (1971) pointed out that the existing published literature indeed did not support the effect. At about the same time, some failures to replicate the sleeper effect were published (Capon \& Hulbert, 1973; Gillig \& Greenwald, 1974; Shulman \& Worrall, 1970). It was not until 1978 that a replicable sleeper effect was reported (Gruder et al., 1978), and it was not until 1986 that the conditions on which this replicable sleeper effect depended were described (Greenwald, Pratkanis, Leippe, \& Baumgardner, 1986; Pratkanis, Greenwald, Leippe, \& Baumgardner, 1988). Those conditions turned out to be a quite small subset of the conditions that were initially claimed to produce the sleeper effect.

Wicker's provocative statement of the attitude-behavior problem led to some notable attempts at resolution. In particular, there have been some well-developed and wellaccepted solutions to the attitude-behavior problem (by

\begin{tabular}{|c|c|}
\hline $\begin{array}{l}\text { Instruction: Rate } \\
\text { your degree of belief } \\
\text { in each of the } \\
\text { following statements } \\
\text { by indicating the } \\
\text { probability that each } \\
\text { is true, on a scale for } \\
\text { which: }\end{array}$ & $\begin{array}{l}\text { Instruction: Rate } \\
\text { your evaluation of } \\
\text { each of the following } \\
\text { attributes on a scale } \\
\text { for which: }\end{array}$ \\
\hline $0=$ not at all true & $-10=\underset{\text { undesirable }}{\text { Extremely }}$ \\
\hline 10 = certainly true & $0=$ Neutral \\
\hline $\begin{array}{l}\text { Social psychologists } \\
\text { are: }\end{array}$ & $\begin{array}{c}+10=\text { Extremely } \\
\text { desirable }\end{array}$ \\
\hline Intelligent & Intelligent \\
\hline Athletic & Athletic \\
\hline Dishonest & Dishonest \\
\hline Brave & Brave \\
\hline
\end{tabular}
Fishbein \& Ajzen [1974; Ajzen \& Fishbein, 1980] and by Fazio \& Zanna [Fazio, 1986; Fazio \& Zanna, 1981; Zanna \& Fazio, 1982]). However, those solutions work by limiting the scope of the attitude concept. Here is

Figure 4. Illustration of the Fishbein multiattribute rating attitude measurement procedure. 
an effective summary statement of these limitations by Myers (1987):

Our attitudes predict our actions (1) if other influences are minimized, (2) if the attitude is specific to the action, and (3) if, as we act, we are conscious of our attitudes, either because something reminds us of them or because we acquired them in a manner that makes them strong. When these conditions are not met, our attitudes seem disconnected from our actions (p. 45).

Myers's conclusion is decidedly embarrassing as a summary of the predictive power of social psychology's major theoretical construct. In the remainder of this paper, I will suggest that the attitude-behavior problem can be solved much more optimistically. The solution that I propose makes use of recent cognitive psychological findings concerning unconscious cognitive processes and implicit memory. As will be seen, this solution calls into question the appropriateness of the presently most favored techniques of attitude measurement.

\section{Some Strong Attitude Effects}

In making the case that attitude is a problematic construct, I have neglected to point out that there are some very reliable and robust findings in which attitudes are centrally involved. In describing these, I hope to make apparent that strong effects of attitude on action can and do occur when the actor is not attentionally focusing on the attitude. This conclusion is almost directly opposite to the one that Myers drew.

An example of a powerful attitude effect-one that might well be taken as a prototype of strong attitude effects-is the halo effect. The halo effect is the tendency to make new positive (or negative) judgments toward a person when a positive (or negative) attitude toward that person already exists. Figure 5 illustrates a halo effect reported by Landy and Sigall (1974). In their research, male subjects judged the quality of a student-authored essay that was provided in a folder that contained additionally only a photograph of the female author, who was either very attractive or unattractive. In addition to varying the attractiveness of the author and having a control (no-photo) condition, the design varied essay quality, which was either good or poor. Landy and Sigall found that the author's attractiveness influenced judgments of essay quality most markedly when the essay was poor in quality.

A second powerful effect is the similarity-attraction effect (or dissimilarity-repulsion effect [Rosenbaum, 1986]) - the tendency to be attracted to people as a function of the similarity of their attitudes to your own. In the research on this effect, the experimenter prepares a description of another person, which consists of a list of that person's opinion responses. Unknown to the subject, the stimulus person's opinion responses are constructed to provide varying degrees of agreement with the subject's own previously reported opinion responses. In the example shown in Figure 2 (based on Byrne, 1962), from 0 to 7 of the stimulus person's opinion responses agreed with those of the subject, who then responded to items

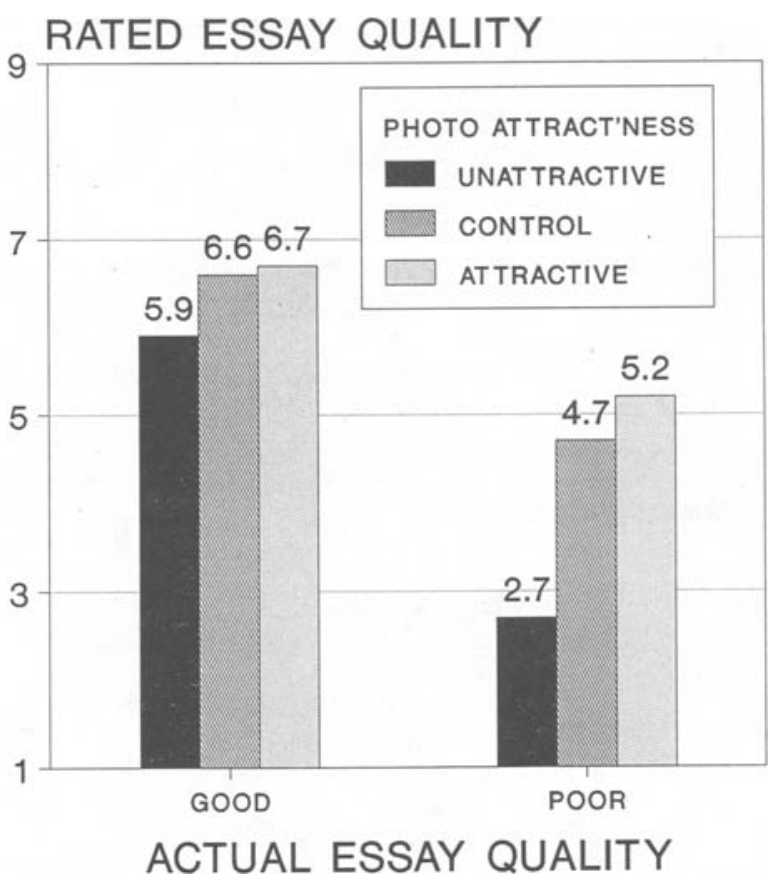

Figure 5. The halo effect. Male subjects' ratings of an essay were strongly influenced by the attractiveness of a photograph of the female author. (Data from Landy \& Sigall, 1974.)

that measured liking for the stimulus person. As can be seen in Figure 6, liking was strongly determined by attitudinal agreement.

A third powerful attitude effect is the cognitive response effect-the tendency to evaluate a persuasive message in a manner consistent with one's existing attitudes. The cognitive response effect is a relative of the similarityattraction effect in the sense that cues indicating agreement with the subject's attitudes lead to liking of the object (person in the similarity-attraction effect, communication in the cognitive response effect) associated with those cues. The cognitive response effect was established in the late 1960s in work done at Ohio State University (Cullen, 1968; Greenwald, 1968, 1969). A particularly impressive demonstration of the effect appeared in a study by Lord, Ross, and Lepper (1979), in which students in favor of or opposed to capital punishment evaluated arguments and evidence on both sides of that issue. Each communication was considered valid by students whose opinions it supported, and invalid by those whose opinions it opposed. (See Figure 7.)

Each of the effects illustrated in Figures 5-7 has been obtained robustly and repeatedly. Furthermore, for these effects, measures of subjects' attitudes typically predict approximately $50 \%$ of the variance in dependent measures. In other words, these are strong effects. Why is it that these attitude effects are strong, when many other attitude effects are fragile? And why is it that none of these robust attitude effects takes the form in which social psychologists expect to find the most substantial effects of attitudes. That is, none of them involves a direct effect 


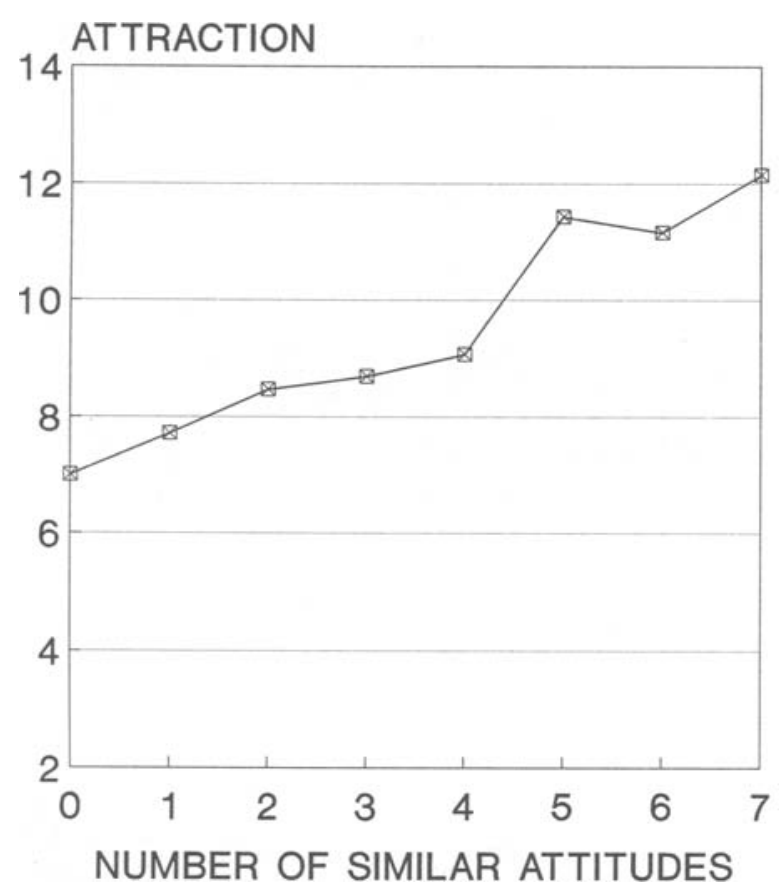

Figure 6. The similarity-attraction effect. Liking for a stimulus person was strongly influenced by the number of attitude items (out of 7) on which the stimulus person agreed with the subject. (Data from Byrne, 1962.)

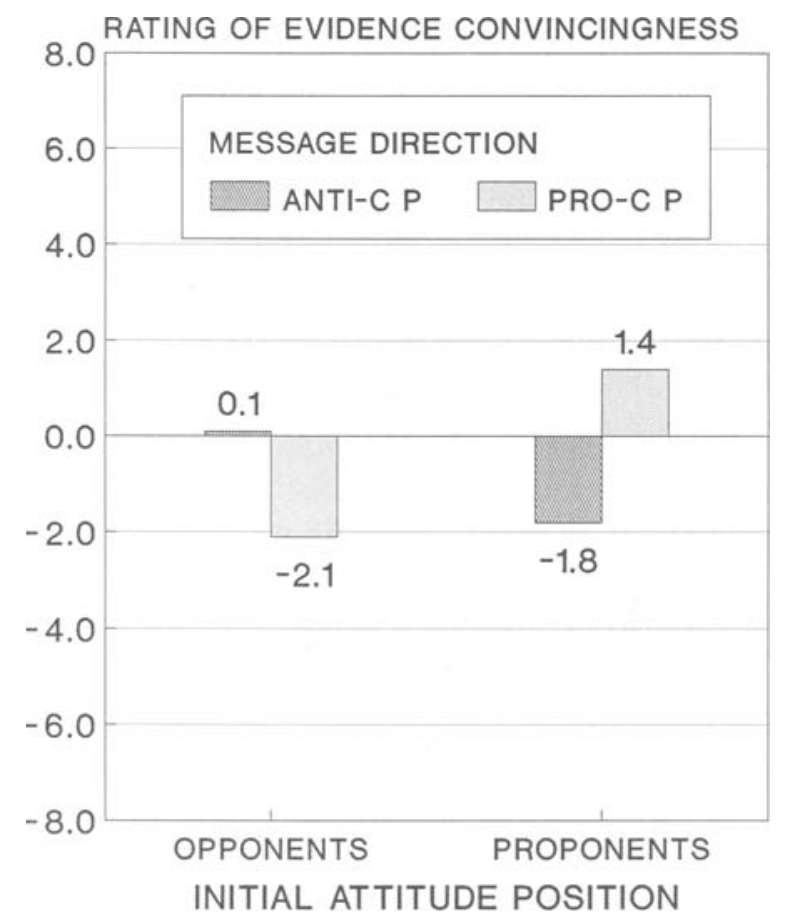

Figure 7. The cognitive response effect. Convincingness of a research study evaluating the deterrent effect of capital punishment was determined by subjects' attitudes for or against capital punishment. (Data from Lord, Ross, \& Lepper, 1979.) of attitude (by which I mean the relation between attitude and behavior toward the same object). Each involves what may be called an indirect effect of attitude, and it seems that these indirect effects are typically stronger and more dependable than direct effects.

\section{Informal Observations}

Informal observations also suggest that indirect effects of attitudes may be powerful. I will give just one example, from a professional activity that is not ordinarily thought to involve attitudes-editorial reviewing of manuscripts.

As a manuscript reviewer, I often cannot help noticing an initial warm, positive reaction when I review a manuscript that cites my work favorably (or maybe just cites it at all), and sometimes I notice the opposite-a colder reaction when some of my work that might have been cited is not mentioned. I know that these reactions interfere with the way my work as reviewer should be done, but it is difficult to avoid these reactions-and it is difficult not to do the review by searching for virtues that will justify the initial warm reaction, or for flaws that will justify the initial cold reaction. Others (Gordon, 1980; Peters \& Ceci, 1982) have suggested that the author's institutional affiliation is another cue that can instigate an attitudinal response in the review process. Such attitudinal reactions constitute forms of discrimination that are every bit as objectionable as racist, ethnic, or sexist prejudice.

\section{Some New Findings}

Before drawing conclusions, I will describe some recent findings that support the earlier suggestion that it is really quite easy to find robust attitude effects when the attitude is involved only indirectly or obliquely in the action.

One such finding - a curious one-is the name letter effect (Nuttin, 1985). This is the finding that people tend to like letters in their names better than letters not in their name. This result is shown in Figure 8, as it was obtained in a dissertation by Johnson (1986). It may also be seen from Johnson's data that the pattern of liking for letters is such that the name letter effect is carried almost entirely by initial letters, and thus might better be called the initial letter effect. For this effect, it is presumably an attitude toward one's self (i.e., self-esteem) that is the indirect determinant of the liking response.

The mere exposure effect is an increase in liking for objects that have been repeatedly encountered. Some recent findings by Jacoby, Kelley, Brown, and Jasechko (1989) show that an effect resembling the mere exposure effect occurs in judgments of famousness. In Jacoby et al.'s experiments, $24 \mathrm{~h}$ after nonfamous names were read as part of a list of both famous and nonfamous names being pronounced, those names were more likely to be mistaken for famous names than were similar names that were being seen for the first time (see Figure 9). This result is especially impressive to an attitude researcher, because (as Jacoby and his coauthors pointed out) the result is an analogue of the sleeper effect, which was pain- 


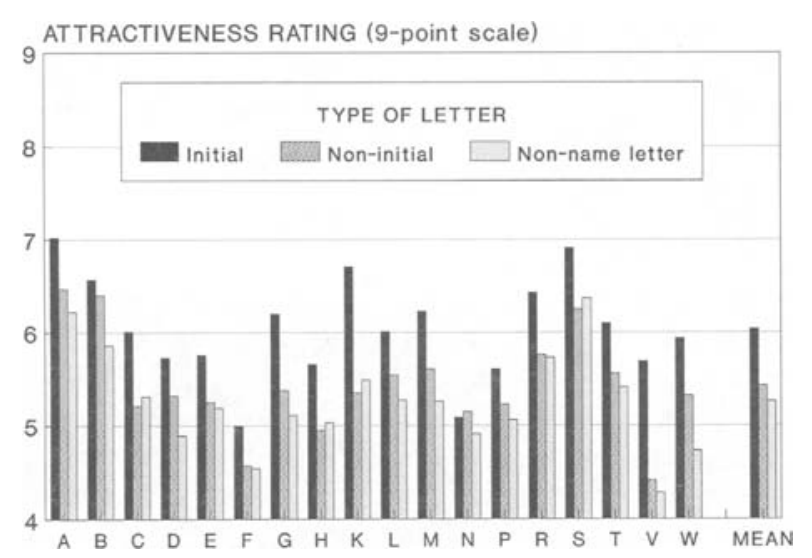

Figure 8. The initial letter effect. Subjects judged letters in their names to be more attractive than those not in their name, with most of this effect being explained by liking for first and last initial letters. (Data provided by 597 subjects, with means based on minimum of 13 observations; from Johnson, 1986.)

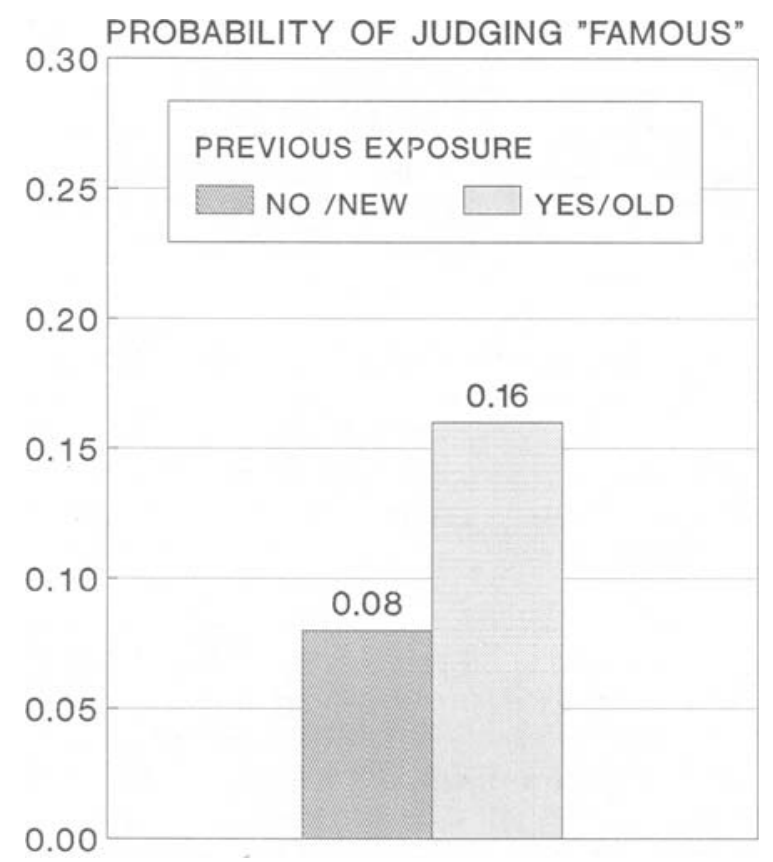

Figure 9. Becoming famous overnight. Nonfamous names read on Day 1 were likely to be mistakenly judged as famous on Day 2. (Data from Jacoby, Kelley, Brown, \& Jasechko, 1989.)

fully difficult to obtain by the standard methods of persuasion research (see the previous discussion).

Another set of recent findings concerns phenomena of prejudice and discrimination. Several studies of racial prejudice have shown that discriminatory judgments can be activated unconsciously (e.g., Devine, 1989; Dovidio, Mann, \& Gaertner, 1989). A new, and moderately disturbing, demonstration of unconsciously activated prejudice was obtained in an as yet unreported study by Mahzarin Banaji and myself, using Jacoby et al.'s (1989) famejudgment task to reveal a form of sex discrimination. We found that the "becoming famous overnight effect" of Jacoby et al. was obtained significantly more strongly with male than with female nonfamous names for both male and female subjects, indicating a greater reluctance to attach the desirable attribute of fame to females than to males (see Figure 10).

The several recent discoveries of unconscious manifestations of prejudice led to a further search for evidence that social scientists (who are widely regarded as being relatively free of prejudice) might display ethnic prejudices. Eric Schuh, Katharina Engnell, and I (Greenwald, Schuh, \& Engnell, 1990) examined citation patterns for authors whose names were selected from the 1987 Social Sciences Citation Index because they could be classified unambiguously as Jewish or Anglo-Saxon in origin. We found (see Figure 11) that Jewish-named authors cited 6\% more authors with Jewish names than did Anglo-Saxonnamed authors; at the same time, Anglo-Saxon-named authors cited $7 \%$ more authors with Anglo-Saxon names than did Jewish-named authors.

\section{Analysis}

The situations that yield ready demonstrations of attitude effects share some properties that provide clues to interpretation. First, the response appears to be under the control of a stimulus feature that is not consciously focused on by the subject. This lack of attention to the critical feature occurs in part because that feature is not directly relevant to the subject's task. (For example, the sex of the unfamiliar name was the controlling but irrele-

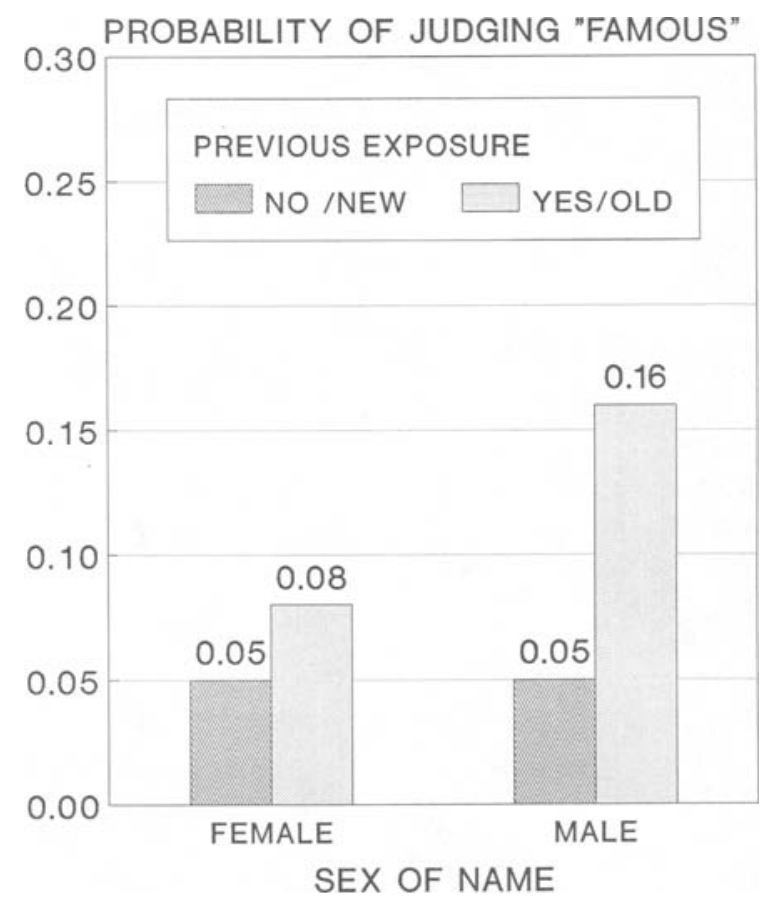

Figure 10. Sex discrimination in famousness judgments. Jacoby et al.'s "becoming famous overnight" effect (see Figure 9) was more likely to occur for male than for female names. (Data from an unpublished study by M. R. Banaji and the author.) 


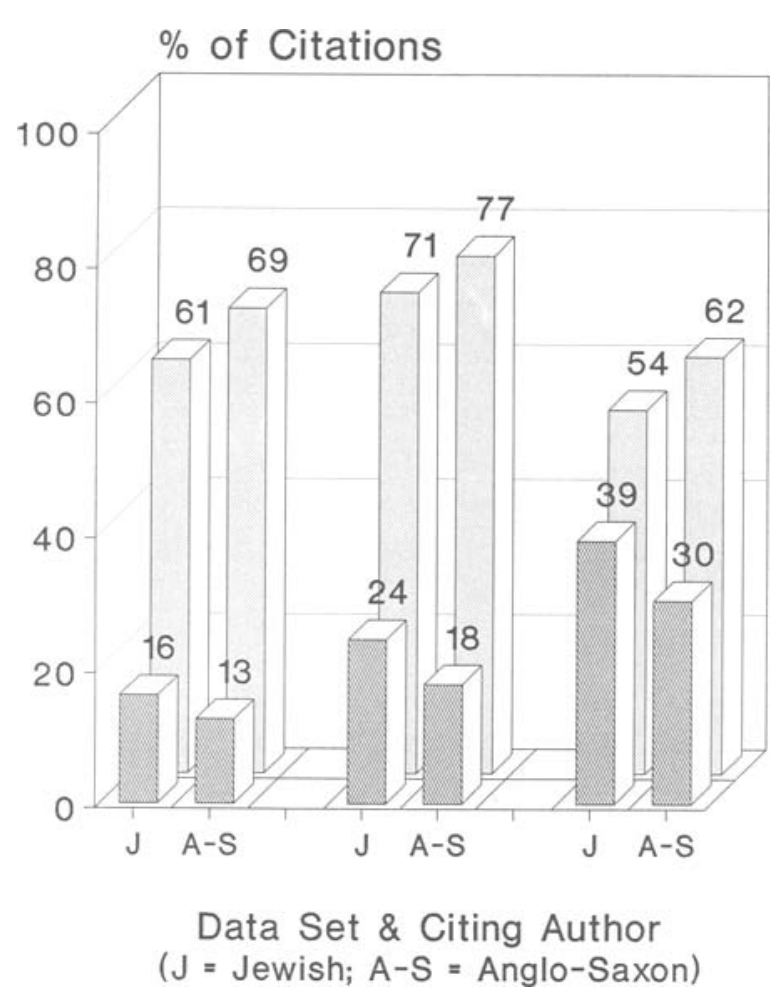

Figure 11. Ethnic bias in scientific citations. Citations of Jewishnamed and Anglo-Saxon-named authors were related to ethnic identification of the citing author's name. (Data from Greenwald, Schuh, \& Engnell, 1990).

vant feature in the sex-discrimination variation of Jacoby et al.'s [1989] 'becoming famous overnight"' result; and the physical attractiveness of the author was the controlling but irrelevant cue in Landy \& Sigall's [1974] halo effect result.) Second, the dependent measures for these effects typically are themselves evaluative judgments. (For example, the responses are such things as evaluations of an argument's quality, a name's famousness, a letter's attractiveness, or an essay's quality.)

There is an obvious connection between these findings and recent memory research that uses indirect measures to assess unconscious or implicit memory (Jacoby \& Witherspoon, 1982; Richardson-Klavehn \& Bjork, 1988; Schacter, 1987). In the attitude effects reviewed above, the subject is in a situation that requires a response to some object; attitude toward an attribute of the object influences the response, and it does so without the subject's being aware that an attitude is being activated. These situations amount to indirect memory tasks for which the response has an evaluative component.

\section{Conclusions}

The results that I have summarized suggest that attitudes may be measured effectively with techniques resembling those used to study implicit memory. This suggestion departs sharply from the currently dominant methods of attitude measurement, which more closely resemble the direct procedures used in studies of conscious or explicit memory. (That is, in responding to the most popular types of attitude measures, which were illustrated near the beginning of this paper, subjects are encouraged both to consider the focal attitude object thoughtfully, and to retrieve knowledge pertinent to their judgments.) In contrast, what I argue to be more effective attitude measures-ones more likely to reveal strong attitude effects-require the subject to respond only to the demands of a current task, without encouraging memory search or otherwise thoughtful analysis.

This conclusion in favor of indirect measurement of attitudes can be illustrated with Landy and Sigall's (1974) halo effect study. In that study, the effect of the author's physical attractiveness on judgments of essay quality would almost certainly be attenuated, eliminated, or maybe even reversed, if the experimenter said to the subject, "In judging the quality of her essay, please notice the writer's attractiveness." Or, in Banaji and Greenwald's adaptation of Jacoby et al.'s (1989) fame-judgment task, the effect of the name's sex might be suppressed if the experimenter said, "Please note that some of the names are male and some are female." Or, Johnson's (1986) initial letter effect might be suppressed if the experimenter said, "Note that some of the letters are ones in your name."

Why should attitude effects be more apparent under indirect testing conditions than under direct ones? One answer might be that attitudes operate unconsciously, and that unconsciously mediated effects are easily disrupted when attention is directed to the action. A second interpretation is that there may often be attitudinal dissociations, meaning that an unconscious attitude differs evaluatively from the conscious attitude toward some object or attribute. Still a third interpretation is that, when attention is focused on the response to an object, more attitudes become activated because more identifications or attributes of the object are activated; because multiple attitudes are likely to influence the evaluative response in competing ways, no attitude effect may be clearly apparent.

It will be interesting to attempt to choose among these explanations. However, no matter which of them is most effective, the implications for attitude measurement are the same, and they are severe. The present state of the art of attitude measurement is based on the assumptionwhich directly conflicts with all three of the hypotheses just suggested - that attitudes are most readily observed when thoughtful attention is focused on the attitude object. We can call these thoughtful types of measures direct, in contrast with the indirect (or unobtrusive, or nonreactive) measures used in studies that yield strong attitude effects.

Because direct measures appear to be at such a disadvantage in the observation of attitude effects, strong attitude effects with direct measures may be observable only under the highly limited conditions that were described in the statement by Myers (1987) quoted earlier. By contrast, investigations of attitudes that involve indirect attitude measures should continue to result in strong effects of attitudes, and they offer the promise of overcoming the construct validity problems that have nagged at attitude research for the past two decades. 


\section{REFERENCES}

AJZEN, I., \& FISHBEIN, M. (1980). Understanding attitudes and predicting social behavior. Englewood Cliffs, NJ: Prentice-Hall.

BRECKLER, S. J. (1984). Empirical validation of affect, behavior, and cognition as distinct components of attitude. Journal of Personality \& Social Psychology, 47, 1191-1205.

BYRNE, D. (1962). Response to attitude similarity-dissimilarity as a function of affiliation need. Journal of Personality, 30, 164-177.

CAPON, N., \& HulBert, J. (1973). The sleeper effect-an awakening. Public Opinion Quarterly, 37, 333-358.

CooK, T. D. (1971). The discounting cue hypothesis and the sleeper effect. Unpublished manuscript, Northwestern University, Department of Psychology.

Coombs, C. H., Dawes, R. M., \& TVERSKY, A. (1972). Mathematical psychology. Englewood Cliffs, NJ: Prentice-Hall.

Cullen, D. M. (1968). Attitude measurement by cognitive sampling. Unpublished doctoral dissertation, Ohio State University.

Devine, P. G. (1989). Stereotypes and prejudice: Their automatic and controlled components. Journal of Personality \& Social Psychology, 56, 5-18.

Dovidio, J. F., MANN, J., \& GAERTNER, S. L. (1989). Resistance to affirmative action: The implications of aversive racism. In F. A. Blanchard \& F. J. Crosby (Eds.), Affirmative action in perspective (pp. 83-102). New York: Springer-Verlag.

FAZIO, R. H. (1986). How do attitudes guide behavior? In R. M. Sorrentino \& E. T. Higgins (Eds.), Handbook of motivation and cognition: Foundations of social behavior (pp. 204-243). New York: Guilford Press.

FAZIO, R. H., \& ZANNA, M. P. (1981). Direct experience and attitudebehavior consistency. In L. Berkowitz (Ed.), Advances in experimental social psychology (Vol. 14, pp. 161-202). New York: Academic Press.

Fishbein, M. (1967a). A behavior theory approach to the relation between beliefs about an object and the attitude toward the object. In M. Fishbein (Ed.), Readings in attitude theory and measurement (pp. 389-400). New York: Wiley.

Fishbein, M. (1967b). A consideration of beliefs and their role in attitude measurement. In M. Fishbein (Ed.), Readings in attitude theory and measurement (pp. 257-266). New York: Wiley.

Fishbein, M., \& AJZEN, I. (1974). Attitudes toward objects as predictors of single and multiple behavior criteria. Psychological Review, 81, 59-74.

Gillig, P. M., \& Greenwald, A. G. (1974). Is it time to lay the sleeper effect to rest? Journal of Personality \& Social Psychology, 29, 132-139.

GoRDON, M. D. (1980). The role of referees in scientific communication. In J. Hartley (Ed.), The psychology of written communication (pp. 263-275). London: Kogan Page.

Greenwald, A. G. (1968). Cognitive learning, cognitive response to persuasion, and attitude change. In A. G. Greenwald, T. C. Brock, \& T. M. Ostrom (Eds.), Psychological foundations of attitudes (pp. 147-170). New York: Academic Press.

Greenwald, A. G. (1969). The open-mindedness of the counterattitudinal role player. Journal of Experimental Social Psychology, 5, 375-388.

Greenwald, A. G., Pratkanis, A. R., Leippe, M. R., \& BaumGARDNER, M. H. (1986). Under what conditions does theory obstruct research progress? Psychological Review, 93, 216-229.

Greenwald, A. G., Schuh, E. S., \& Engnell, K. (1990). Ethnic bias in scientific citations. Unpublished manuscript, University of Washington, Department of Psychology.

Gruder, C. L., Cook, T. D., Hennigan, K. M., Flay, B. R., Alessis, C., \& HalamaJ, J. (1978). Empirical tests of the absolute sleeper effect predicted from the discounting cue hypothesis. Journal of Personality \& Social Psychology, 36, 1061-1074.

Hovland, C. I., Lumsdaine, A. A., \& ShefField, F. D. (1949). Experiments on mass communications. Princeton, NJ: Princeton University Press.

JaCOBY, L. L., Kelley, C., Brown, J., \& JASEChKo, J. (1989). Becoming famous overnight: Limits on the ability to avoid unconscious influences of the past. Journal of Personality \& Social Psychology, 56, 326-338.

JACOBY, L. L., \& WithersPoON, D. (1982). Remembering without awareness. Canadian Journal of Psychology, 36, 300-324.

Johnson, M. M. S. (1986). The initial letter effect: Ego-attachment or mere exposure? Unpublished doctoral dissertation, Ohio State University, Department of Psychology.

LANDY, D., \& SigALL, H. (1974). Beauty is talent: Task evaluation as a function of the performer's physical attractiveness. Journal of Personality \& Social Psychology, 29, 299-304.

LiKeRT, R. (1932). A technique for the measurement of attitudes. Archives of Psychology, No. 140, 44-53.

LORD, C. G., Ross, L., \& LEPPER, M. R. (1979). Biased assimilation and attitude polarization: The effects of prior theories on subsequently considered evidence. Journal of Personality \& Social Psychology, 37, 2098-2109.

Myers, D. G. (1987). Social psychology (2nd ed.). New York: McGraw-Hill.

Nutrin, J. M. (1985). Narcissism beyond Gestalt and awareness: The name letter effect. European Journal of Social Psychology, 15, 353-361.

Osgood, C. E., Suci, G. J., \& Tannenbaum, P. H. (1957). The measurement of meaning. Urbana: University of Illinois Press.

Ostrom, T. M. (1968). The relationship between the affective, behavioral, and cognitive components of attitude. Journal of Experimental Social Psychology, 5, 12-30.

Peters, D. P., \& CeCI, S. J. (1982). Peer-review practices of psychological journals: The fate of published articles, submitted again. $B e-$ havioral \& Brain Sciences, 5, 187-255.

Pratkanis, A. R., Greenwald, A. G., Leippe, M. R., \& BaumGARDNER, M. H. (1988). In search of reliable persuasion effects: III. The sleeper effect is dead. Long live the sleeper effect. Journal of Personality \& Social Psychology, 54, 203-218.

Richardson-KlaAvehn, A., \& BJorK, R. A. (1988). Measures of memory. Annual Review of Psychology, 39, 475-543.

Ronis, D. L., Baumgardner, M. H., LeipPe, M. R., Cacioppo, J. T., \& Greenwald, A. G. (1977). In search of reliable persuasion effects: I. A computer-controlled procedure for studying persuasion. Journal of Personality \& Social Psychology, 35, 548-569.

Rosenbaum, M. E. (1986). The repulsion hypothesis: On the nondevelopment of relationships. Journal of Personality \& Social Psychology, 51, 1156-1166.

SCHACTER, D. L. (1987). Implicit memory: History and current status. Journal of Experimental Psychology: Learning, Memory, \& Cognition, 13, 501-518.

Shulman, G. I., \& Worrall, C. (1970). Salience patterns, source credibility, and the sleeper effect. Public Opinion Quarterly, 34, 371-382.

Thurstone, L. L., \& Chave, E. J. (1929). The measurement of attitude. Chicago: University of Chicago Press.

WICKER, A. W. (1969). Attitudes vs. actions: The relationship of verbal and overt behavioral responses to attitude objects. Journal of Social Issues, 25, 41-78.

ZANNA, M. P., \& FAZIo, R. H. (1982). The attitude-behavior relation: Moving toward a third generation of research. In M. P. Zanna, E. T. Higgins, \& C. P. Herman (Eds.), Consistency in social behavior: The Ontario Symposium (Vol. 2, pp. 283-301). Hillsdale, NJ: Erlbaum. 